\title{
ANALISIS PENGARUH PROFESIONALISME, KOMPETENSI, BUDAYA KERJA, DAN IKLIM ORGANISASI TERHADAP KEDISIPLINAN PEGAWAI PADA PDAM TIRTA KAJEN KAB. PEKALONGAN
}

\section{Santi Sucinngtyas}

Sekolah Tinggi Ilmu Ekonomi (STIE) Assholeh Pemalang Jawa Tengah, Indonesia

Email: suciningtyassanti@gmail.com

\section{Abstract}

The purpose of this study was to analyze and obtain empirical evidences of the influence of professionalism, competence, work culture, and organizational climate on the employee discipline. This study used a saturated sample technique because the respondents of the study were 52 employees. The testing in this study was carried out by validity, reliability, classical assumptions, multiple linear regression analysis and hypothesis testing in the form of the $t$ test and $F$ test. The results showed that to test the hypothesis partially using the $t$ test. The $t$ value for the variable professionalism $\left(X_{1}\right)$ was 2,324 , the competency variable $\left(X_{2}\right)$ was 2,119 , the work culture variable $\left(X_{3}\right)$ was 2,943 and the organizational climate variable $\left(X_{4}\right)$ was 3,586. In conclution, all of the variables had an influence on the employee discipline. Based on the results, it was obtained that the Fcount was 26,544 showing that they all had an influence. The determinant coefficient $\left(R^{2}\right)$ was $69.3 \%$, which means that the remaining $30.7 \%$ for other variables that were not included in the equation model. From the description of the results, it was shown that either partially or simultaneously all independent variables, whether professionalism, competence, work culture, or organizational climate had a significant influence on the dependent variabel, namely discipline.

Keywords: discipline; professionalism; competence; work culture; and organizational climate
Abstrak
Tujuan penelitian ini adalah untuk menganalisis dan memperoleh bukti secara empirirs pengaruh profesionalisme, kompetensi, budaya kerja, dan iklim organisasi terhadap kedisiplinan pegawai Pada penelitian ini menggunakan teknik sampel jenuh karena responden yang diteliti berjumlah 52 pegawai. Adapun pengujian pada penelitian ini dilakukan dengan uji validitas, reliabilitas, asumsi klasik, analisis regresi linier berganda dan uji hipotesis berupa uji t dan uji F. Hasil pennelitian menunjukkan untuk pengujian hipotesis secara parsial digunakan uji $\mathrm{t}$, diperoleh nilai thitung untuk variabel profesionalisme $\left(\mathrm{X}_{1}\right)$ sebesar 2,324, variabel kompetensi $\left(\mathrm{X}_{2}\right)$ sebesar 2,119 variabel budaya kerja $\left(\mathrm{X}_{3}\right)$ sebesar 2,943 dan variabel iklim organisasi $\left(\mathrm{X}_{4}\right)$ sebesar 3,586 dengan demikian dalam pengujian ini berarti semuanya memiliki pengaruh. Dari hasil uji F diperoleh Fhitung sebesar 26,544 yang menjelaskan bahwa secara bersama-sama juga mennjukkan memiliki

$\begin{array}{ll}\text { How to cite: } & \text { Sucinngtyas, Santi (2021) Analisis Pengaruh Profesionalisme, Kompetensi, Budaya Kerja, dan Iklim } \\ & \text { Organisasi terhadap Kedisiplinan Pegawai Pada PDAM Tirta Kajen Kab. Pekalongan. Syntax Literate. } \\ & 6(5) . \text { http://dx.doi.org/10.36418/syntax-literate.v6i5.2721 } \\ \text { E-ISSN: } & \text { 2548-1398 } \\ \text { Published by: } & \text { Ridwan Institute }\end{array}$


penggaruh. Koefisien determinan $\left(\mathrm{R}^{2}\right)$ sebesar $69,3 \%$ yang berarti sisanya $30,7 \%$ dipengaruhi variabel lain yang tidak terdapat dalam model persamaan tersebut. Dari uraian hasil penelitian tadi dapat disimpulkan bahwa baik secara parsial maupun simultan semua variabel independen baik Profesionalisme, Kompetensi, Budaya Kerja, maupun Iklim Organisasi memiliki pengaruh terhadap mariabel dependennya yaitu kedisiplinan.

Kata Kunci: kedisiplinan; profesionalisme; kompetensi; budaya kerja; iklim organisasi.

\section{Pendahuluan}

Faktor sumber daya manusia merupakan komponen yang perlu mendapat perhatian lebih, apalagi pada era globalisasi. Penekanan pada keunggulan bersaing memaksa perusahan untuk lebih ekstra. Jadi manusia dapat dipandang sebagai penggerak utama dan penentu karena ditangan manusia segala iovasi akan direalisasikan ssampai terwujudnya tujuan perusahaan (Dkk, 2018).

Perusahaan Daerah Air Minum (PDAM) Tirta Kajen Kabupaten Pekalongan adalah salah satu perusahaan daerah di Kabupaten Pekalongan yang selalu mengedepankan prestasi baik prestasi pegawainya. Seiring dengan pekembangan dan pembangunan PDAM senantiasa berbenah dalam segala hal agar kebutuhan masyarakat terpenuhi. Dari beberapa fakta yang ada dilapangan ada tingkat kedisiplinan pegawai PDAM masih perlu ditingkatkan seperti menyelesaikan pekerjaan belum sesaui harapan lembaga secara maksimal, masih ada keterlambatan, semangat kerja harus di tambah lagi, dan etos dalam bekerja yang harus lebih rutin diingatkan secara berkala.

\section{Tabel 1}

Data Tindak Pelanggaran Disiplin Kerja Pegawai

\begin{tabular}{cccc}
\hline No & Tingkat hukuman & Sanksi hukuman & Jumlah \\
\hline 1 & Ringan & Teguran lisan & 3 orang \\
\hline 2 & Sedang & Surat peringatan & 1 orang \\
& & $\begin{array}{c}\text { Penundaan kenaikan pangkat } \\
\text { / golonganata }\end{array}$ & 1 orang \\
& Berat & Penurunan pangkat / golongan & 2 orang \\
& & Mutasi & 1 orang \\
\hline 3 & & Jumlah & 8 orang \\
\hline
\end{tabular}

Sumber: data sekunder

Dari tabel di atas membuktikan bahwa tingkat kedisiplinan pegawai terhadap peraturan disiplin masih kurang. Sehingga perlu adanya pengawasan penerapan disiplin serta pendampingan dalam bekerja para pegawai pada PDAM Tirta Kajen Kabupaten Pekalongan.

Profesionalisme dan kompetensi di PDAM Tirta Kajen Kabupaten Pekalongan harus dimiliki oleh pegawainya. Dalam praktek di lapangan, dalam memberikan pelayanan kepada masyarakat, para pegawai masih perlu meningkatkan keandalan. Pada 
saat jam sibuk terkadang ada masyarakat yang membutuhkan pelayanan belum ditindaklanjuti secara langsung.

Dalam hal budaya kerja dalam organisasi terlihat masih harus ditingkatkan seperti di perusahaan dapat dilihat dari tabel berikut:

Tabel 2

Data Perkembangan budaya kerja

\begin{tabular}{|c|c|c|c|c|c|c|}
\hline \multirow{2}{*}{ No. } & \multirow{2}{*}{ Indikator } & \multicolumn{5}{|c|}{ Penilaian } \\
\hline & & SB & B & CK & TB & STB \\
\hline 1. & Dedikasi & & $\mathbf{N}$ & & & \\
\hline 2. & Loyalitas & & & $\mathbf{N}$ & & \\
\hline 3. & Tanggungjawab & & & $\mathbf{N}$ & & \\
\hline 4. & Kerjasama & & & $\mathbf{N}$ & & \\
\hline 5. & Mutu kerja & & & $\mathbf{N}$ & & \\
\hline
\end{tabular}

Kedisiplinan mnenjadi salah satu perilaku yang harus dimiliki oleh pegawai untuk tercapaiya tujuan suatu perusahaan. Kedisiplinan adalah kesadaran dan kesediaan seseorang menaati semua peraturan dan norma-norma sosial yang berlaku (Hasibuan, 2011), sedangkan disiplin kerja adalah keadaan tertib baik seorang maupun kelompok dalam suatu perusahaan yang menjalankan peraturan perusahaan (Hidayat \& Taufiq, 2012). Beberapa penelitian tentang budaya kerja terhadap kedisiplinan antara lain (Ahmad, 2018; Sofyan, Jabbar, \& Sunarti, 2019) dengan hasil penelitian budaya kerja dan kepemimpinan berpengaruh terhadap kedisiplinan pegawai. Sedangkan penelitian (Puspita, 2018) juga menunjukkan bahwa budaya kerja dan iklim kerja dapat mempengaruhi kedisiplinan. Beberapa jurnal yang menyunjukan pengaruh iklim organisasi dalam upaya pencapaian tujuan perusahaan adalah (Ariyanti, Miyono, \& Retnaningdyastuti, 2019; de Jesus \& Supartha, 2019; Zhra Mauli Hermaya, 2018). Jurnal tentang keterkaitan profesionalisme sebagaimana penelitian yang telah dilakukan oleh (Reinhard J. Rumimpunu, Victor P.K. Lengkong, 2018; Sudirman, 2018). Selain itu beberapa penelitian tentang pengaruh kompetensi seperti yang tertulis dalam hasil penelitian.

Dalam penelitian ini peneliti ingin mengetahui secara mendalam hubungan berbagai faktor-faktor yang dapat mempengaruhi tingkat kedisiplinan di PDAM Tirta Kajen Kabupaten Pekalongan. Terkait berbagai permasalahanyang sudah diuraikan diatas maka penulis tertarik mengadakan penelitian dengan judul "Analisis Pengaruh Profesionalisme, Kompetensi, Budaya Kerja dan Iklim Organisasi Terhadap Kedisiplinan Pegawai pada PDAM Tirta Kajen Kabupaten Pekalongan”.

\section{Metode Penelitian}

Metode yang digunakan dalam penelitian ini adalah metode kualitatif. Populasi dalam penelitian ini adalah para pegawai PDAM Tirta Kabupaten Pekalongan semuannya berjumlah 52 orang. Karena jumlah populasinya termasuk dalam populasi 
yang kecil yaitu di bawah 100 orang maka sekaligus sebagai sampel yang disebut sebagai sampel jenuh (Siyoto \& Sodik, 2015).

Analisis data dalam penelitian ini adalah termasuk dalam penelitian kuantitatif, yaitu menyampaikan hasil penelitian dalam bentuk uraian angka-angka hasil uji matematik (Siyoto \& Sodik, 2015). Dalam penelitian ini menggunakan Program SPSS (Ghozali, 2016) untuk uji instrumen dengan uji validitas dan reliabilitas, melakukan juga uji uji asumsi klasik terdiri dari uji linearitas, uji multikolinearitas, uji autokorelasi serta analisis regresi berganda dilakukan untuk menguji pengaruh simultan dari beberapa variabel bebas terhadap satu variabel terikat yang berskala interval. Sedangkan Untuk pengujian hipotesis menggunakan Uji t (uji parsial), Uji F (uji simultan) dan koefisien determinasi (R2).

\section{Hasil dan Pembahasan}

1. Analisis Data

\section{a. Uji Instrumen Tingkat Validitas dan Reliabilitas}

1) Uji Validitas

Uji validitas adalah suatu ukuran yang menunjukan tingkat-tingkat kevalidan atau kesahihan suatu instrumen. Suatu instrumen yang valid atau sahih mempunyai validitas tinggi. Uji Validitas Item Pertanyaan Variabel Profesionalisme $\left(\mathrm{X}_{1}\right)$.

Tabel 3

Rangkuman Hasil Analisis Uji Validitas Item Pertanyaan Masing-Masing Variabel

\begin{tabular}{cccc}
\hline Profesionalisme & $\mathrm{r}_{\text {hitung }}$ & $\mathrm{r}_{\text {tabel }}$ & Keterangan \\
\hline 1. & 0,639 & 0,273 & VALID \\
\hline 2. & 0,809 & 0,273 & VALID \\
\hline 3. & 0,774 & 0,273 & VALID \\
\hline 4. & 0,830 & 0,273 & VALID \\
\hline 5. & 0,802 & 0,273 & VALID \\
\hline 6. & 0,703 & 0,273 & VALID \\
\hline 7. & 0,705 & 0,273 & VALID \\
\hline Kompetensi & $\mathrm{r}_{\text {hitung }}$ & $\mathrm{r}_{\text {tabel }}$ & VALID \\
\hline 1. & 0,727 & 0,273 & VALID \\
\hline 2. & 0,856 & 0,273 & VALID \\
\hline 3. & 0,880 & 0,273 & VALID \\
\hline 4. & 0,914 & 0,273 & VALID \\
\hline 5. & 0,882 & 0,273 & Keterangan \\
\hline Budaya Kerja & $\mathrm{r}_{\text {hitung }}$ & $\mathrm{r}_{\text {tabel }}$ & VALID \\
\hline 1. & 0,932 & 0,273 & VALID \\
\hline 2. & 0,928 & 0,273 & VALID \\
\hline 3. & 0,922 & 0,273 & VALID \\
\hline 4. & 0,906 & 0,273 & Keterangan \\
\hline Iklim Organisasi & $\mathrm{r}_{\text {hitung }}$ & $\mathrm{r}_{\text {tabel }}$ & VALID \\
\hline 1. & 0,884 & 0,273 & VALID \\
\hline 2. & 0,881 & 0,273 & VALID
\end{tabular}


Analisis Pengaruh Profesionalisme, Kompetensi, Budaya Kerja, dan Iklim Organisasi terhadap Kedisiplinan Pegawai Pada PDAM Tirta Kajen Kab. Pekalongan

\begin{tabular}{cccc}
\hline 4. & 0,868 & 0,273 & VALID \\
\hline 5. & 0,910 & 0,273 & VALID \\
\hline 6. & 0,758 & 0,273 & VALID \\
\hline 7. & 0,824 & 0,273 & VALID \\
\hline Kinerja & $\mathrm{r}_{\text {hitung }}$ & $\mathrm{r}_{\text {tabel }}$ & Keterangan \\
\hline 1. & 0,902 & 0,273 & VALID \\
\hline 2. & 0,903 & 0,273 & VALID \\
\hline 3. & 0,844 & 0,273 & VALID
\end{tabular}

Sumber : Data primer yang diolah

2) Uji Reliabilitas

Reliabilitas ditunjukan pada tabel rangkuman uji reliabilitas dari masingmsing variabel sebagai berikut :

Tabel 4

Rangkuman Hasil Analisis Uji Reliabilitas per Variabel

\begin{tabular}{cccc}
\hline Variabel & $\mathrm{r}_{\text {hitung }}$ & $\mathrm{r}_{\text {tabel }}$ & Keterangan \\
\hline Profesionalisme $\left(\mathrm{X}_{1}\right)$ & 0,869 & 0,273 & Reliabel \\
\hline Kompetensi $\left(\mathrm{X}_{2}\right)$ & 0,905 & 0,273 & Reliabel \\
\hline Budaya Kerja $\left(\mathrm{X}_{3}\right)$ & 0,940 & 0,273 & Reliabel \\
\hline Iklim Organisasi $\left(\mathrm{X}_{4}\right)$ & 0,941 & 0,273 & Reliabel \\
\hline Kedisiplinan Pegawai $(\mathrm{Y})$ & 0,898 & 0,273 & Reliabel \\
\hline
\end{tabular}

Sumber : Data primer yang diolah

Jadi dapat disimpulkan bahwa untuk item pertanyaan variabel Profesionalisme $\left(\mathrm{X}_{1}\right)$, variabel Kompetensi $\left(\mathrm{X}_{2}\right)$, variabel Budaya Kerja $\left(\mathrm{X}_{3}\right)$, variabel Iklim Organisasi $\left(\mathrm{X}_{4}\right)$ dan variabel Kedisiplinan Pegawai $(\mathrm{Y})$ adalah reliabel karena nilai $r_{\text {hitung }}>r_{\text {tabel }}$.

\section{b. Uji Asumsi Klasik}

1) Hasil Uji Linearitas

Tabel 5

Rangkuman Hasil Analisis Uji Linearitas

\begin{tabular}{cccc}
\hline Variabel & Linearity & Signifikansi & Keterangan \\
\hline Profesionalisme $\left(\mathrm{X}_{1}\right)$ & 0,000 & 0,05 & Linear \\
\hline Kompetensi $\left(\mathrm{X}_{2}\right)$ & 0,000 & 0,05 & Linear \\
\hline Budaya Kerja $\left(\mathrm{X}_{3}\right)$ & 0,000 & 0,05 & Linear \\
\hline Iklim Organisasi $\left(\mathrm{X}_{4}\right)$ & 0,000 & 0,05 & Linear \\
\hline
\end{tabular}

Sumber : Data primer yang diolah

Maka dapat disimpulkan bahwa antara masing-masing variabel dan Kedisiplinan Pegawai (Y) terdapat hubungan yang linear karena nilai signifikansi kurang dari 0,05. 
2) Hasil Uji Normalitas

Tabel 6

Hasil Analisis Uji Normalitas

\begin{tabular}{|c|c|c|c|c|c|c|}
\hline \multicolumn{7}{|c|}{ One-Sample Kolmogorov-Smirnov Test } \\
\hline & & $\begin{array}{l}\text { Profesionalis } \\
\text { me_X1 }\end{array}$ & $\begin{array}{l}\text { Kompeten } \\
\text { si_X2 }\end{array}$ & $\begin{array}{c}\text { Budaya_Ker } \\
\text { ja_X3 }\end{array}$ & $\begin{array}{c}\text { Iklim_Organis } \\
\text { asi_X4 }\end{array}$ & $\begin{array}{c}\text { Kedisiplinan_Peg } \\
\text { awai_Y }\end{array}$ \\
\hline \multicolumn{2}{|l|}{$\mathrm{N}$} & 52 & 52 & 52 & 52 & 52 \\
\hline \multirow{2}{*}{$\begin{array}{l}\text { Normal } \\
\text { Paramete } \\
\text { rs }^{\mathrm{a}, \text {, b }}\end{array}$} & Mean & 24.98 & 17.27 & 14.02 & 24.23 & 16.31 \\
\hline & $\begin{array}{l}\text { Std. } \\
\text { Deviat } \\
\text { ion }\end{array}$ & 2.783 & 2.801 & 2.974 & 3.974 & 2.356 \\
\hline \multirow{3}{*}{$\begin{array}{l}\text { Most } \\
\text { Extreme } \\
\text { Differen } \\
\text { ces }\end{array}$} & $\begin{array}{l}\text { Absol } \\
\text { ute }\end{array}$ & .131 & .181 & .155 & .161 & .173 \\
\hline & $\begin{array}{l}\text { Positiv } \\
\mathrm{e}\end{array}$ & .127 & .165 & .155 & .136 & .112 \\
\hline & $\begin{array}{l}\text { Negati } \\
\text { ve }\end{array}$ & -.131 & -.181 & -.130 & -.161 & -.173 \\
\hline \multicolumn{2}{|c|}{$\begin{array}{l}\text { Kolmogorov- } \\
\text { Smirnov Z }\end{array}$} & .947 & 1.308 & 1.120 & 1.160 & 1.249 \\
\hline \multicolumn{2}{|c|}{$\begin{array}{l}\text { Asymp. Sig. (2- } \\
\text { tailed) }\end{array}$} & .331 & .065 & .163 & .135 & .088 \\
\hline \multicolumn{7}{|c|}{ a. Test distribution is Normal. } \\
\hline \multicolumn{7}{|c|}{ b. Calculated from data. } \\
\hline
\end{tabular}

Sumber : Data primer yang diolah

Dari tabel diatas maka dapat disimpulkan bahwa data pada variabel Profesionalisme $\left(\mathrm{X}_{1}\right)$, variabel Kompetensi $\left(\mathrm{X}_{2}\right)$, variabel Budaya Kerja $\left(\mathrm{X}_{3}\right)$, variabel Iklim Organisasi $\left(\mathrm{X}_{4}\right)$ dan variabel Kedisiplinan Pegawai (Y) berdistribusi normal.

3) Hasil Uji Multikolinearitas

Tabel 7

Hasil Uji Multikolinearitas

Coefficients $^{\mathrm{a}}$

\begin{tabular}{lccc}
\hline & Model & \multicolumn{2}{c}{ Collinearity Statistics } \\
\cline { 3 - 4 } & & Tolerance & VIF \\
\hline 1. & (Constant) & 706 & \\
\hline 2. & Profesionalisme_X1 & 660 & 1.416 \\
\hline 3. & Kompetensi_X2 & 702 & 1.516 \\
\hline 4. & Budaya_Kerja_X3 & 627 & 1.425 \\
\hline 5. & Iklim_Organisasi_X4 & & 1.596 \\
\hline
\end{tabular}

a. Dependent Variable: Kedisiplinan_Pegawai_Y

Sumber : Data primer yang diolah 
Karena nilai VIF (Variance Inflation Faction) jauh dibawah angka 10. Dari tabel tersebut diperoleh bahwa semua variabel bebas memiliki nilai tolerance berada dibawah 1 dan nilai VIF (Variance Inflation Faction) jauh di bawah angka 10. Dengan demikian dalam model ini tidak ada masalah multikolinearitas.

4) Hasil Uji Heteroskedastisitas

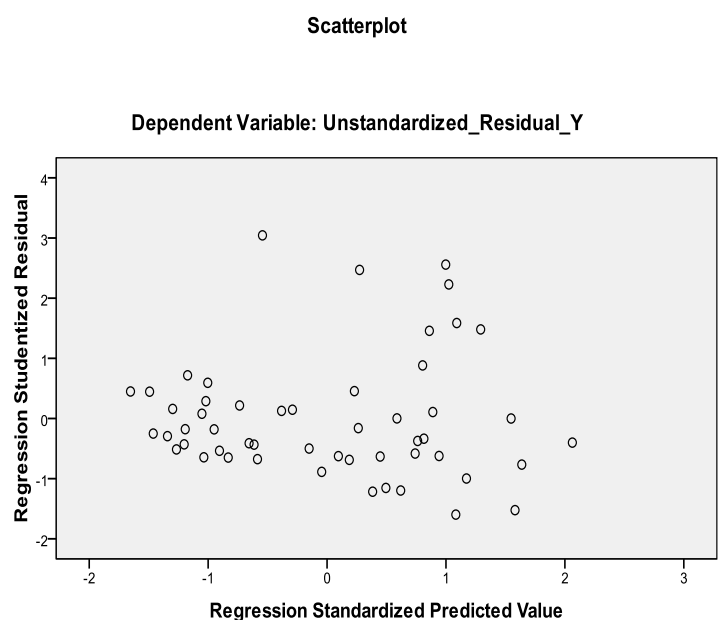

\section{Gambar 1}

\section{Uji Heteroskedastisitas}

Dengan demikian dapat disimpulkan bahwa model regresi ini tidak terjadi heteroskedastisitas. Akan tetapi analisis dengan grafik plot memiliki kelemahan dalam keakuratan menginterprestasikannya, oleh sebab itu perlu dilakukan uji statistik untuk lebih menjamin keakuratan hasil.

5) Autokorelasi

Uji Autokorelasi bertujuan untuk menguji apakah dalam model regresi linier ada korelasi antara kesalahan pengganggu pada periode t-1 (sebelumnya) hasilnya sebagai berikut:

Tabel 8

Uji Durbin-Watson

\begin{tabular}{|c|c|c|c|c|c|}
\hline \multicolumn{6}{|c|}{ Model Summary ${ }^{b}$} \\
\hline Model & $\mathrm{R}$ & R Square & $\begin{array}{l}\text { Adjusted R } \\
\text { Square }\end{array}$ & $\begin{array}{l}\text { Std. Error of the } \\
\text { Estimate }\end{array}$ & Durbin-Watson \\
\hline 1 & $.833^{\mathrm{a}}$ & .693 & .667 & 1.359 & 1.860 \\
\hline \multicolumn{6}{|c|}{$\begin{array}{l}\text { a. Predictors: (Constant), Iklim_Organisasi_X4, Budaya_Kerja_X3, } \\
\text { Profesionalisme_X1, Kompetensi_X2 }\end{array}$} \\
\hline \multicolumn{6}{|c|}{ b. Dependent Variable: Kedisiplinan_Pegawai_Y } \\
\hline
\end{tabular}




\section{c. Analisis Regresi Linier Berganda}

Berdasarkan perhitungan dengan menggunakan Program SPSS versi diperoleh hasil regresi linier berganda pada persamaan sebagai berikut :

$$
\mathrm{Y}=0,110+0,189 \mathrm{X}_{1}+0,177 \mathrm{X}_{2}+0,225 \mathrm{X}_{3}+0,217 \mathrm{X}_{4}+\text { error } \text {. }
$$

Dari hasil persamaan regresi linier berganda di atas dapat diketahui bahwa peningkatan Kedisiplinan Pegawai di PDAM Tirta Kajen Kabupaten Pekalongan dipengaruhi secara positif dan signifikan oleh Profesionalisme, Kompetensi, Budaya Kerja dan Iklim Organisasi.

\section{d. Pengujian Hipotesis}

1. Pengujian Hipotesis secara parsial dengan menggunakan Uji $t$

Untuk mengetahui thitung digunakan uji $\mathrm{t}$ dengan tujuan menguji hipotesis pertama, kedua, ketiga dan keempat berpengaruh terhadap Kedisiplinan Pegawai (Y) dengan taraf kesalahan 0,05 atau 5\% dengan level of significance $95 \%$ dengan rumus sebagai berikut:

Tabel 9

Hasil Analisis Uji t

\begin{tabular}{|c|c|c|c|c|c|c|}
\hline \multicolumn{7}{|c|}{ Coefficients $^{\mathrm{a}}$} \\
\hline & \multirow{2}{*}{ Model } & $\begin{array}{r}\text { Unstand: } \\
\text { Coeffic }\end{array}$ & $\begin{array}{l}\text { rdized } \\
\text { ents }\end{array}$ & $\begin{array}{c}\text { Standardized } \\
\text { Coefficients }\end{array}$ & \multirow[b]{2}{*}{$\mathbf{T}$} & \multirow[b]{2}{*}{ Sig } \\
\hline & & B & $\begin{array}{c}\text { Std. } \\
\text { Error }\end{array}$ & Beta & & \\
\hline 1. & (Constant) & 110 & 1.830 & & 060 & 952 \\
\hline 2. & Profesionalisme_X1 & 189 & 081 & 223 & 2.324 & 025 \\
\hline 3. & Kompetensi_X2 & 177 & 084 & 211 & 2.119 & 039 \\
\hline 4. & Budaya_Kerja_X3 & 225 & 076 & 284 & 2.943 & 005 \\
\hline 5. & Iklim_Organisasi_X4 & 217 & 061 & 366 & 3.586 & 001 \\
\hline
\end{tabular}

Sumber : Data primer yang diolah

Jadi, dengan demikian hipotesis yang menyatakan secara parsial variabel Profesionalisme $\left(\mathrm{X}_{1}\right)$, Kompetensi $\left(\mathrm{X}_{2}\right)$, Budaya Kerja $\left(\mathrm{X}_{3}\right)$ dan Iklim Organisasi $\left(\mathrm{X}_{4}\right)$ secara parsial berpengaruh terhadap Kedisiplinan Pegawai (Y) diterima.

2. Uji keberartian koefisien determinan $\left(\mathrm{R}^{2}\right)$ dan regresi linier berganda secara keseluruhan dengan Uji F.

Untuk mengetahui ada tidaknya pengaruh antara variabel terikat dengan variabel bebas, maka digunakan analisa koefisien determinan $\left(\mathrm{R}^{2}\right)$ sebagai berikut :

Tabel 10

Hasil Analisa Koefisien Determinan $\left(\mathbf{R}^{2}\right)$

\begin{tabular}{ccccc}
\hline \multicolumn{5}{c}{ Model Summary $^{\mathbf{b}}$} \\
\hline Model & $\mathbf{R}$ & R Square & $\begin{array}{c}\text { Adjusted R } \\
\text { Square }\end{array}$ & $\begin{array}{c}\text { Std. Error of the } \\
\text { Estimate }\end{array}$ \\
\hline 1 & $833^{\mathrm{a}}$ & 693 & 667 & 1.359 \\
\hline
\end{tabular}




\begin{tabular}{l}
\hline a. Predictors: (Constant), Iklim_Organisasi_X4, Budaya_Kerja_X3, \\
Profesionalisme_X1, Kompetensi_X2 \\
b. Dependent Variable: Kedisiplinan_Pegawai_Y \\
Sumber : Data primer yang diolah
\end{tabular}

Untuk mengukur besarnya pengaruh variabel bebas (Profesionalisme, Kompetensi, Budaya Kerja dan Iklim Organisasi) secara bersama-sama sebagai berikut:

\section{Tabel 11}

Hasil Analisis Uji F

\begin{tabular}{ccccccc}
\hline \multicolumn{7}{c}{ ANOVA $^{\mathbf{b}}$} \\
\hline Model & $\begin{array}{c}\text { Sum of } \\
\text { Squares }\end{array}$ & Df & $\begin{array}{c}\text { Mean } \\
\text { Square }\end{array}$ & F & Sig \\
\hline 1. & Regression & 196.219 & 4 & 49.055 & 26.544 & $000^{\mathrm{a}}$ \\
\hline 2. & Residual & 86.858 & 47 & 1.848 & & \\
\hline 3. & Total & 283.077 & 51 & & & \\
\hline
\end{tabular}

a. Predictors: (Constant), Iklim_Organisasi_X4, Budaya_Kerja_X3, Profesionalisme_X1, Kompetensi_X2

b. Dependent Variable: Kedisiplinan_Pegawai_Y

Sumber : Data primer yang diolah

Oleh karena itu, hipotesis yang menyatakan bahwa secara simultan variabel Profesionalisme $\left(\mathrm{X}_{1}\right)$, Kompetensi $\left(\mathrm{X}_{2}\right)$, Budaya Kerja $\left(\mathrm{X}_{3}\right)$ dan Iklim Organisasi $\left(\mathrm{X}_{4}\right)$ berpengaruh secara bersama-sama (simultan) dan signifikan terhadap Kedisiplinan Pegawai (Y) di PDAM Tirta Kajen Kabupaten Pekalongan diterima.

\section{Kesimpulan}

Berdasarkan hasil penelitian yang sudah dilakukan, diketahui bahwa bahwa baik secara parsial maupun simultan variabel profesionalisme, kompetensi, budaya kerja dan iklim organisasi memiliki pengaruh terhadap kedisiplinan dari para pegawai di PDAM Tirta Kajen Kabupaten Pekalongan. Sedangkan apabila dilihat dari hasil pengaruh masing-masing variabel maka variabel iklim organisasilah yang paling dominan. Dengan demikian pihak PDAM perlu terus menupayakan supaya tetap terjaga situai bekerja yang nyaman sehingga segala bentuk peraturan dan norma-norma yang ada akan dapat dilaksnakan secara maksimal. 


\section{BIBLIOGRAFI}

Ahmad, Mauledy. (2018). Pengaruh Budaya Kerja dan Kepemimpinan Terhadap Kedisiplinan Pegawai pada Badan Perencanaan dan Pembangunan Kabupaten Kerinci. Kolektivita, Vol 1(1). Google Scholar

Ariyanti, Ika, Miyono, Noor, \& Retnaningdyastuti, Retnaningdyastuti. (2019). Pengaruh Kompetensi Manajerial Kepala Sekolah Dan Iklim Organisasi Terhadap Profesionalisme Guru Sekolah Dasar Negeri Se Kecamatan Tengaran Kabupaten Semarang. Jurnal Manajemen Pendidikan (JMP), 8(2). Google Scholar

De Jesus, Luis, \& Supartha, Wayan Gede. (2019). Pengaruh Iklim Organisasi, Kompetensi Dan Motivasi Terhadap Kinerja Pegawai Di Kantor Perdagangan Industri Dan Lingkungan Hidup Di Timor Leste. E-Jurnal Ekonomi Dan Bisnis Universitas Udayana, 61-78. Google Scholar

Deswin Liando Singal. (2018). Anlisis Pengaruh Iklim Organisasi, Komitmen Oranisasi Terhadap Disiplin Kerja Pegawai (Studi di Bank Mandiri Area Manado). Jurnal EMBA, 6(4).

Ghozali, Imam. (2016). Aplikasi Analisis Multivariete Dengan Program IBM SPSS 23 Edisi 8 (8th ed.). Semarang: Universitas Diponogoro. Google Scholar

Hasibuan, Malayu. (2011). Manajemen Sumber dan Daya Manusia. Jakarta: Bumi Aksara. Google Scholar

Hidayat, Zainul, \& Taufiq, Muchamad. (2012). Pengaruh Lingkungan Kerja dan Disiplin Kerja serta Motivasi Kerja Terhadap Kinerja Karyawan Perusahaan Daerah Air Minum (PDAM) Kabupaten Lumajang. Wiga: Jurnal Penelitian Ilmu Ekonomi, 2(1), 36644. Google Scholar

Puspita, Gita. (2018). Pengaruh Budaya Kerja Dan Iklim Kerja Terhadap Disiplin Kerja Pegawai Kantor Pertanahan Kota Bogor. Jurnal Visionida, 4(1), 23-33. Google Scholar

Reinhard J. Rumimpunu, Victor P.K. Lengkong, Jantje L. (2018). Pengaruh Profesionalisme, Kompetensi dan Disiplin Kerja Terhadap kinerja Pegawai di Badan Perencanaan Pembagunan Daerah (BAPEDA) Provinsi Sulut. Jurnal EMBA, 6(4). Google Scholar

Siyoto, Sandu, \& Sodik, Muhammad Ali. (2015). Dasar metodologi penelitian. Literasi Media Publishing. Google Scholar

Sofyan, Sofyan, Jabbar, Abdul, \& Sunarti, Sunarti. (2019). Pengaruh Budaya Kerja Terhadap Kedisiplinan Pegawai Di Kantor Desa Bina Baru Kecamatan Kulo Kabupaten Sidenreng Rappang. Moderat: Jurnal Ilmiah Ilmu Pemerintahan, 5(1), 56-69. Google Scholar 
Analisis Pengaruh Profesionalisme, Kompetensi, Budaya Kerja, dan Iklim Organisasi terhadap Kedisiplinan Pegawai Pada PDAM Tirta Kajen Kab. Pekalongan

Sudirman, Sudirman. (2018). Pengaruh Kompetensi Profesional Guru, Motivasi Kerja Dan Disiplin Kerja Terhadap Kinerja Guru Di Smp It Budi Mulia Padang. Jurnal Kepemimpinan Dan Pengurusan Sekolah, 3(2), 197-208. Google Scholar

Zhra Mauli Hermaya, Ahyar Yuniawan. (2018). Analisis Penaruh Iklim Organisasi, Komunikasi Organisasi Terhadap Disiplin Kerja (Studi Kasus PadaKaryawan Divisi Operasional PT. Plasa Simpanglima Semarang. Diponegoro Journal Of Management, 7(1).

\section{Copyright holder:}

Santi Sucinngtyas (2021)

First publication right:

Journal Syntax Literate

This article is licensed under:

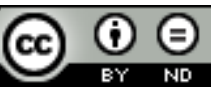

